\title{
The Use of Thalidomide in Severe Refractory Anaemia Due to Gastric Antral Vascular Ectasia (GAVE) in Cirrhosis?
}

\author{
Marcelo Aveiro $^{1}$, Tatiana Rodrigues ${ }^{1}$, Tiago Rabadão ${ }^{1}$, Filipa Ferreira ${ }^{1}$, Mariana Teixeira ${ }^{1}$, Ana Oliveira ${ }^{1}$, Inês Vasconcelos ${ }^{2}$ \\ ${ }^{1}$ Department of Internal Medicine, Centro Hospitalar do Baixo Vouga, Aveiro, Portugal \\ ${ }^{2}$ Department of Family Medicine, USF Atlântico Norte, Gafanha da Nazaré, Portugal
}

Received: $25 / 10 / 2020$

Accepted: $28 / 10 / 2020$

Published: $18 / 11 / 2020$ How to cite this article: Aveiro M, Rodrigues T, Rabadão T, Ferreira F, Teixeira M, Oliveira A, Vasconcelos I. The use of thalidomide in severe refractory
anaemia due to gastric antral vascular ectasia (GAVE) in cirrhosis? EJCRIM 2020;7: doi:10.12890/2020_002099.

Conflicts of Interests: The Authors declare that there are no competing interests.

This article is licensed under a Commons Attribution Non-Commercial 4.0 License

\section{ABSTRACT}

Gastric antral vascular ectasia (GAVE) is a rare cause of upper gastrointestinal bleeding associated with cirrhosis. The first-line treatment is endoscopic therapy with argon plasma coagulation (APC). There is a high recurrence rate, but some evidence suggests that thalidomide could play an important role in controlling refractory anaemia due to GAVE. The authors present the case of a cirrhotic patient with a recent diagnosis of GAVE, who underwent multiple endoscopic treatments and blood transfusions because of haematemesis. The patient started thalidomide and 6 months later, there was no recurrence of haematemesis and haemoglobin levels were stable, with no reported adverse effects.

\section{LEARNING POINTS}

- The chronic bleeding associated with gastric antral vascular ectasia (GAVE) presenting with cirrhosis is more severe than that associated with portal hypertensive gastropathy.

- Argon plasma coagulation remains the first-line treatment, but GAVE has a high recurrence rate.

- Thalidomide could be an effective and safe option for recurrent bleeding due to GAVE in patients with cirrhosis.

\section{KEYWORDS}

GAVE, thalidomide, cirrhosis

\section{INTRODUCTION}

Gastric antral vascular ectasia (GAVE) is a rare cause of upper gastrointestinal bleeding, and accounts for approximately $4 \%$ of all nonvariceal gastrointestinal bleeding ${ }^{[1]}$. The majority of patients present with iron-deficiency anaemia secondary to occult blood loss, and about $60-70 \%$ of patients are transfusion-dependent ${ }^{[2,3]}$. GAVE is commonly associated with chronic illnesses, most frequently liver cirrhosis and connective tissue diseases ${ }^{[4]}$. The prevalence in the general population is unknown, but a prevalence of $12 \%$ was reported in patients with cirrhosis ${ }^{[5]}$. Endoscopic therapy is the mainstay of management for patients with GAVE ${ }^{[6]}$. In patients with active haemorrhage or anaemia, the available evidence favours endoscopic therapy with argon plasma coagulation (APC) ${ }^{[7,8]}$, with the disadvantage of a high recurrence rate of $30-60 \%{ }^{[6]}$. A few medical therapies have been proposed to reduce the need for endoscopic intervention. Thalidomide has previously been shown to exert a potent antiangiogenic effect in experimental studies ${ }^{[9]}$. This is maybe due to the reduction in vascular endothelial growth factor (VEGF) levels in these patients. 


\section{CASE DESCRIPTION}

The authors present the case of an 84-year-old woman with recently diagnosed cryptogenic cirrhosis with portal hypertension and GAVE. She was referred to the emergency department in June 2019 because of severe anaemia (haemoglobin of $5.8 \mathrm{~g} / \mathrm{dl}$ ) that required red blood cell (RBC) transfusion and endoscopic treatment with APC. Between June 2019 and January 2020, the patient visited the emergency department seven times because of severe episodes of haematemesis. She was transfused with a total of 15 units of red blood cells to maintain haemoglobin levels above $8 \mathrm{~g} / \mathrm{dl}$ and underwent five endoscopic treatments with APC in 6 months. During the last hospitalization, endoscopic treatment was considered no longer effective so it was decided to start therapy with 50 mg/day thalidomide for 2 weeks increasing to $100 \mathrm{mg} /$ day. Haemoglobin levels, renal function and hepatic enzymes were closely monitored during this initial phase and remained stable. The patient was discharged with close follow-up and, 6 months after thalidomide initiation, there was no recurrence of haematemesis. Haemoglobin levels remained steady at $8.9 \mathrm{~g} / \mathrm{dl}$, with no adverse effects reported.

\section{DISCUSSION}

GAVE is a poorly understood pathology that was first reported by Rider et al. in $1953^{[10]}$. It is a rare cause of upper gastrointestinal bleeding (UGIB) and most commonly affects females (about 71\%), who are an average age of 73 years at presentation. Patients with GAVE associated with cirrhosis have a worse Child-Pugh classification, and present with more severe chronic bleeding than those with portal hypertensive gastropathy ${ }^{[11]}$. GAVE, unlike portal hypertensive gastropathy, does not respond to beta-blockers or nitrates ${ }^{[10,12]}$.

Endoscopic therapy with APC is the first-line treatment ${ }^{[7,8]}$, but due to the high recurrence rate and the burden associated with a repeated invasive procedure, other strategies have been proposed. There is evidence to support the efficacy of medical therapy as an alternative to laser therapy in GAVE ${ }^{[8]}$. Multiple drugs, such as oestrogen-progesterone ${ }^{[13,14]}$, octreotide ${ }^{[15,16]}$, steroids ${ }^{[17,18]}$, tranexamic acid ${ }^{[19]}$, and even bevacizumab ${ }^{[7]}$, have been tried to control GAVE-related bleeding. In 2006, the first patient with refractory anaemia secondary to GAVE was successfully treated with thalidomide ${ }^{[20]}$. Since then, thalidomide has sometimes been administered to cirrhotic patients with gastrointestinal bleeding related to vascular malformations. There are some case reports on the efficacy of thalidomide in this setting ${ }^{[21-23]}$. However, in the particular context of cirrhosis and GAVE, the efficacy of thalidomide still remains to be adequately studied. The side effects of thalidomide are generally not severe (fatigue, peripheral neuropathy and skin rash) and they resolve after drug withdrawal ${ }^{[24]}$. In very rare cases, thalidomide can induce hepatotoxicity ${ }^{[25]}$, and therefore, liver enzymes should be closely monitored. 


\section{REFERENCES}

1. Su T, Yang L. Gastric antral vascular ectasia: a case report and literature review. World Chinese J Dig 2017;25(5):476-478.

2. Liberski SM, McGarrity TJ, Hartle RJ, Varano V, Reynolds D. The watermelon stomach: long-term outcome in patients treated with Nd:YAG laser therapy. Gastrointest Endosc 1994;40(5):584-587.

3. Gostout CJ, Viggiano TR, Ahlquist DA, Wang KK, Larson MV, Balm R. The clinical and endoscopic spectrum of the watermelon stomach. J Clin Gastroenterol 1992;15(3):256263.

4. Dulai GS, Jensen DM, Kovacs TOG, Gralnek IM, Jutabha R. Endoscopic treatment outcomes in watermelon stomach patients with and without portal hypertension. Endoscopy 2004;36(1):68-72

5. Yamada M, Ichikawa M, Takahara O, Tsuchida T, Ishihara A, Yamada M, et al. Gastroduodenal vascular ectasia in patients with liver cirrhosis. Dig Endosc 1999;11(3):241-245.

6. Patwardhan VR, Cardenas A. Review article: The management of portal hypertensive gastropathy and gastric antral vascular ectasia in cirrhosis. Aliment Pharmacol Ther 2014;40(4):354-362.

7. Santos S, Bernardes C, Borges V, Ramos G. Gastric antral vascular ectasia (GAVE) and hereditary hemorrhagic telangiectasia (HHT): two different conditions, one treatment. Ann Hematol 2020;99(2):367-369.

8. Thonhofer R, Siegel C, Trummer M, Gugl A. Medical versus laser therapy for gastric antral vascular ectasia: comment on the clinical images by Thonhofer et al. Arthritis Rheum 2010;62(11):3517-3518.

9. D'Amato RJ, Loughnan MS, Flynn E, Folkman J. Thalidomide is an inhibitor of angiogenesis. Proc Natl Acad Sci U S A 1994;91(9):4082-4085.

10. Rider JA, Klotz AP, Kirsner JB. Gastritis with veno-capillary ectasia as a source of massive gastric hemorrhage. Gastroenterology 1953;24(1):118-123.

11. Sebastian S, O'Morain CA, Buckley MJM. Review article: Current therapeutic options for gastric antral vascular ectasia. Aliment Pharmacol Ther 2003;18(2):157-165.

12. Jabbari M, Cherry R, Lough JO, Daly DS, Kinnear DG, Goresky CA. Gastric antral vascular ectasia: the watermelon stomach. Gastroenterology 1984;87(5):1165-1170.

13. Moss SF, Ghosh P, Thomas DM, Jackson JE, Calam J. Gastric antral vascular ectasia: maintenance treatment with oestrogen-progesterone. Gut 1992;33(5):715-717

14. Tran A, Villeneuve JP, Bilodeau M, Willems B, Marleau D, Fenyves D, et al. Treatment of chronic bleeding from gastric antral vascular ectasia (GAVE) with estrogen-progesterone in cirrhotic patients: an open pilot study. Am J Gastroenterol 1999;94(10):2909-2911.

15. Nardone G, Rocco A, Balzano T, Budillon G. The efficacy of octreotide therapy in chronic bleeding due to vascular abnormalities of the gastrointestinal tract. Aliment Pharmacol Ther 1999;13(11):1429-1436.

16. Barbara G, De Giorgio R, Salvioli B, Stanghellini V, Corinaldesi R. Unsuccessful octreotide treatment of the watermelon stomach. J Clin Gastroenterol 1998;26(4):345-346.

17. Bhowmick BK. Watermelon stomach treated with oral corticosteroid. J R Soc Med 1993;86(1):52.

18. Calam J, Walker RJ. Antral vascular lesion, achlorhydria, and chronic gastrointestinal blood loss: response to steroids. Dig Dis Sci 1980;25(3):236-239.

19. McCormick PA, Ooi H, Crosbie O. Tranexamic acid for severe bleeding gastric antral vascular ectasia in cirrhosis. Gut 1998;42(5):750-752.

20. Dunne KA, Hill J, Dillon JF. Treatment of chronic transfusion-dependent gastric antral vascular ectasia (watermelon stomach) with thalidomide. Eur J Gastroenterol Hepatol 2006;18(4):455-456.

21. Karajeh MA, Hurlstone DP, Stephenson TJ, Ray-Chaudhuri D, Gleeson DC. Refractory bleeding from portal hypertensive gastropathy: a further novel role for thalidomide therapy? Eur J Gastroenterol Hepatol 2006;18(5):545-548

22. Moser S, Tischer A, Karpi A, Schleicher M, Stavjanik S, Gschwantler M. Evidence that thalidomide is effective in recurrent bleeding from watermelon stomach associated with liver cirrhosis. Endoscopy 2014;46:E384.

23. Serrano AG, León R, Sayago M, Márquez JL. Thalidomide treatment in cirrhotic patients with severe anemia secondary to vascular malformations. Dig Dis Sci 2012;57(4):11121113.

24. Kamalaporn P, Saravanan R, Cirocco M, May G, Kortan P, Kandel G, et al. Thalidomide for the treatment of chronic gastrointestinal bleeding from angiodysplasias: a case series. Eur J Gastroenterol Hepatol 2009;21(12):1347-1350.

25. Hanje AJ, Shamp JL, Thomas FB, Meis GM. Thalidomide-induced severe hepatotoxicity. Pharmacotherapy 2006;26(7):1018-1022. 